\section{CardioRenal Medicine}

\title{
Effects of Bardoxolone Methyl on QT Interval in Healthy Volunteers
}

\author{
Melanie P. Chin Shannon Rich Angie Goldsberry Megan O'Grady \\ Colin J. Meyer
}

Product Development, Reata Pharmaceuticals, Irving, TX, USA

\section{Keywords}

Bardoxolone methyl · QT interval · Chronic kidney diseases

\begin{abstract}
Background: Bardoxolone methyl has been shown to increase eGFR in several clinical trials, including a phase 3 trial in patients with type 2 diabetes and stage 4 CKD (BEACON), which was terminated early due to an increase in heart failure events in bardoxolone methyl-treated patients. A separate, "thorough QT" study was conducted in parallel with BEACON to evaluate the cardiovascular safety of bardoxolone methyl in healthy subjects. Methods: Subjects in the "thorough QT" study were randomized to receive bardoxolone methyl $20 \mathrm{mg}$ (therapeutic dose) or $80 \mathrm{mg}$ (supratherapeutic dose), placebo, or moxifloxacin (400 mg; an active comparator). ECG results and supine blood pressure measurements were analyzed. The effects of bardoxolone methyl on QT interval changes from baseline were quantified compared to the effect of placebo by calculating mean, time-matched, placebo-corrected, baseline-adjusted QTcF values $(\triangle \Delta \mathrm{QTCF})$ after 6 days of daily administration of bardoxolone methyl. Results: The study was halted early due to emerging safety information from the BEACON trial; however, $142 / 179$ patients received all doses of the study drug and completed the study. For both bardoxolone methyl-treated groups (20 and $80 \mathrm{mg}$ ), the upper limits of the 2 -sided $90 \%$ confidence interval for $\Delta \Delta \mathrm{QTCF}$ were less than the significance limit $(10 \mathrm{~ms})$ at all time points. Changes in blood pressure were similar in all treatment groups, and no serious adverse events were reported. Conclusions: In healthy subjects, treatment with 20 or 80 mg bardoxolone methyl did not affect the QTcF interval.

(c) 2019 The Author(s)

Published by S. Karger AG, Basel
\end{abstract}


Chin et al.: Effects of Bardoxolone Methyl on QT Interval

\section{Introduction}

Bardoxolone methyl activates the nuclear factor E2-related factor 2 (Nrf2) pathway, which plays an important role in maintaining kidney function and structure [1-5]. Bardoxolone methyl interacts with cysteine residues on kelch-like ECH-associated protein 1 (Keap1) allowing Nrf2 translocation to the nucleus and subsequent up-regulation of a multitude of antioxidant genes $[1,5,6]$. Additionally, the structure and activity profile of bardoxolone methyl resemble those of the cyclopentenone prostaglandins, endogenous Nrf2 activators that exert anti-inflammatory effects by inhibiting the proinflammatory nuclear factor $\kappa \mathrm{B}$ (NFKB) pathway [7-10].

Preclinical studies have shown that bardoxolone methyl and close analogs have beneficial activity in animal models of kidney disease, including amelioration of murine ischemic acute kidney injury [11], attenuation of kidney interstitial inflammation and fibrosis in mice with proteinuria induced by protein overload $[12,13]$, and protection against fibrosis in a $5 / 6$ nephrectomy model of chronic kidney disease (CKD) [14].

Improvements in kidney function, assessed using measured inulin clearance, measured creatinine clearance, and estimated glomerular filtration rate (eGFR), have also been observed consistently with bardoxolone methyl treatment in several clinical trials [15-18]. The largest of these was a multinational, randomized, double-blind, placebo-controlled, phase 3 outcome trial, which enrolled 2,185 patients with type 2 diabetes mellitus and CKD stage 4 (Bardoxolone Methyl Evaluation in Patients with Chronic Kidney Disease and Type 2 Diabetes: The Occurrence of Renal Events [BEACON]) [17]. The BEACON trial was terminated early because of safety concerns, largely driven by a significant increase in heart failure events within the first 4 weeks of drug exposure. The cause of these events was subsequently determined to be acute fluid retention without evidence of direct cardiotoxicity in a subset of patients with identifiable risk factors (elevated baseline B-type natriuretic peptide and prior history of heart failure) $[19,20]$, which allowed for exclusion of at-risk patients in subsequent trials.

A separate "thorough QT" cardiovascular safety study (NCT01689116) was conducted in parallel with BEACON that was designed to evaluate the effect of bardoxolone methyl on the QT/QTc interval at therapeutic (20 $\mathrm{mg}$ ) and supratherapeutic doses (80 $\mathrm{mg}$ ) in healthy subjects, as recommended by the ICH E14 Guidance on the Clinical Evaluation of QT/QTc Interval Prolongation and Proarrhythmic Potential for Non-Antiarrhythmic Drugs [21]. We performed analyses from the cardiovascular safety study to further characterize the pharmacological effects of bardoxolone methyl on cardiac repolarization, as detected by changes in the QT/QTc interval.

\section{Methods}

This single-center, multiple-dose, randomized, double-blind, double-dummy, placebo-controlled, active-comparator, parallel study (NCT01689116) evaluated 4 treatments. Subjects were randomized to receive bardoxolone methyl (20 or $80 \mathrm{mg}$ ), placebo, or moxifloxacin (400 $\mathrm{mg}$ ) as the active comparator. Bardoxolone methyl and placebo capsules were administered once daily for 6 consecutive days, and 1 encapsulated tablet of moxifloxacin or moxifloxacin placebo was administered on study day 6. All subjects returned for a follow-up visit on study day 13 and had a follow-up phone call on study day 21. The study was also halted on October 18, 2012, due to emerging safety information for bardoxolone methyl from the BEACON study. Healthy males and females between 18 and 50 years of age with a body mass index (BMI) $\geq 18$ but $\leq 32 \mathrm{~kg} / \mathrm{m}^{2}$ were eligible for the study. Subjects with a history of unexplained syncope, cardiac arrest, cardiac arrhythmia (unexplained or torsades de pointes), structural heart disease, or a family history of long QT syndrome were excluded from the study. Additionally, subjects with evidence of cardiac conduction abnormalities, supine systolic blood pressure outside of the 90-145 mm Hg range, or diastolic blood pressure outside of the 45-96 $\mathrm{mm} \mathrm{Hg}$ range at the screening visit were excluded. 
Table 1. Summary of demographics and baseline characteristics

\begin{tabular}{|c|c|c|c|c|c|}
\hline \multirow[t]{2}{*}{ Variable } & \multirow{2}{*}{$\begin{array}{l}\text { Placebo } \\
n=45\end{array}$} & \multicolumn{2}{|c|}{ Bardoxolone methyl } & \multirow{2}{*}{$\begin{array}{l}\text { Moxifloxacin } \\
400 \mathrm{mg} \\
n=45\end{array}$} & \multirow{2}{*}{$\begin{array}{l}\text { All subjects } \\
n=179\end{array}$} \\
\hline & & $\begin{array}{l}20 \mathrm{mg} \\
n=45\end{array}$ & $\begin{array}{l}80 \mathrm{mg} \\
n=44\end{array}$ & & \\
\hline \multicolumn{6}{|l|}{ Means (SD) } \\
\hline Age, years & $33(8)$ & $30(8)$ & $32(9)$ & $34(9)$ & $33(9)$ \\
\hline Weight, kg & $78.8(10.6)$ & $71.0(14.4)$ & $78.5(11.0)$ & 76.7 (12.1) & $76.2(12.4)$ \\
\hline Height, $\mathrm{cm}$ & $170.4(8.4)$ & $168.8(11.0)$ & $174.4 .(9.7)$ & $170.4(9.5)$ & $171.0(9.8)$ \\
\hline Body mass index, $\mathrm{kg} / \mathrm{m}^{2}$ & 27.1 (2.7) & $24.9(3.3)$ & $25.8(3.3)$ & $26.3(3.2)$ & $26.0(3.2)$ \\
\hline Serum creatinine, $\mu \mathrm{mol} / \mathrm{L}$ & 78.4 (15.9) & 75.9 (14.8) & 77.8 (12.9) & $79.4(18.1)$ & $76.8(13.8)$ \\
\hline QTcF, $\mathrm{ms}^{\mathrm{a}}$ & $406.8(16.2)$ & $410.7(15.9)$ & $407.2(17.7)$ & $405.8(17.7)$ & $407.6(16.9)$ \\
\hline \multicolumn{6}{|l|}{$n(\%)$} \\
\hline \multicolumn{6}{|l|}{ Sex } \\
\hline Male & $25(55.6)$ & $24(53.3)$ & $24(54.5)$ & $23(51.1)$ & $96(53.6)$ \\
\hline Female & $20(44.4)$ & $21(46.7)$ & $20(45.5)$ & $22(48.9)$ & $83(46.4)$ \\
\hline \multicolumn{6}{|l|}{ Race } \\
\hline White & $22(48.9)$ & $21(46.7)$ & $27(61.4)$ & $21(46.7)$ & $91(50.8)$ \\
\hline Black/African American & $20(44.4)$ & $20(44.4)$ & $16(36.4)$ & $20(44.4)$ & $76(42.5)$ \\
\hline Multiple & $2(4.4)$ & $1(2.2)$ & $1(2.3)$ & $3(6.7)$ & 7 (3.9) \\
\hline Other & $1(2.2)$ & $2(4.4)$ & 0 & 0 & $3(1.7)$ \\
\hline Asian & 0 & $1(2.2)$ & 0 & $1(2.2)$ & $2(1.1)$ \\
\hline \multicolumn{6}{|l|}{ Ethnicity } \\
\hline Non-Hispanic or -Latino & $37(82.2)$ & $37(82.2)$ & $38(86.4)$ & $41(91.1)$ & $153(85.5)$ \\
\hline Hispanic or Latino & $8(17.8)$ & 8 (17.8) & $6(13.6)$ & $4(8.9)$ & $26(14.5)$ \\
\hline
\end{tabular}

a Baseline QTcF derived from the average of triplicate values from the first ECG assessment on study day -1 .

Electrocardiograms (ECGs) were obtained digitally using a Mortara X-12+ECG continuous 12-lead digital recorder, and triplicate ECGs (approximately $1 \mathrm{~min}$ apart) were extracted from the continuous data at specified time points during screening and on study days $-1,1,6$, and 13 . Evaluation of the effect of bardoxolone methyl on QT intervals was conducted in accordance with the International Conference on Harmonization E14 Guidance. Supine blood pressure was also measured during screening and on study days $-2,-1$, $1,4,6$, and 13. The QT interval data were corrected for heart rate using Fridericia's (QTcF) corrections.

The effects of bardoxolone methyl at 20- and 80-mg doses on QT interval changes were quantified relative to the effect of placebo by calculating mean, time-matched, placebo-corrected, baseline-adjusted $\mathrm{QTcF}$ values (i.e., $\Delta \Delta \mathrm{QTcF}$ ) on study day 6. Least-square means were estimated using an analysis of covariance (ANCOVA) model with fixed effects for treatment plus a continuous covariate for baseline values. At each time point on study day 6, the difference in least-square means was estimated between each bardoxolone methyl dose and placebo (with placebo as reference) with the corresponding (2-sided) $90 \%$ CI.

\section{Results}

\section{Patient Population}

A summary of demographics by treatment group from the cardiovascular safety study is presented in Table 1. Overall, 179 subjects were enrolled in the cardiovascular safety study. The 179 healthy adult subjects in this study had a mean age of 33 years (range 18-50 years), mean weight of $76.2 \mathrm{~kg}$ (range $48.1-116.9 \mathrm{~kg}$ ), and a mean BMI of $26.0 \mathrm{~kg} / \mathrm{m}^{2}$ (range $18.3-32.0 \mathrm{~kg} / \mathrm{m}^{2}$ ). There were 96 (53.6\%) male and 83 (46.4\%) female subjects. Most subjects were white (91 [50.8\%]) or black/African-American (76 [42.5\%]) and non-Hispanic or -Latino (153 [85.5\%]). The demographic characteristics for the 4 treatment groups were comparable. Because the study was halted, only 142 subjects received all doses of the study drug and completed the study. 


\section{CardioRenal Medicine}

Fig. 1. Placebo-corrected changes from baseline in QTcF with bardoxolone methyl (BARD) in a cardiovascular safety study from a multiple-dose, randomized, double-blind, placebo-controlled cardiovascular safety "thorough QT" study in healthy volunteers. Data plotted are mean $( \pm 90 \% \mathrm{CI})$ timematched, placebo-corrected QTcF changes from baseline $(\Delta \Delta \mathrm{QT} \mathrm{TF})$ $0.5-24 \mathrm{~h}$ after the dose on study day 6 for subjects administered $20 \mathrm{mg}(n=37)$ or $80 \mathrm{mg}(n=33)$ of bardoxolone methyl for 6 consecutive days versus subjects administered placebo $(n=36)$.

\begin{tabular}{l|l}
\hline Cardiorenal Med 2019;9:326-333 \\
\hline DOI: 10.1159/000500736 & $\begin{array}{l}\text { @ 2019 The Author(s). Published by S. Karger AG, Basel } \\
\text { www.karger.com/crm }\end{array}$ \\
\hline
\end{tabular}

Chin et al.: Effects of Bardoxolone Methyl on QT Interval
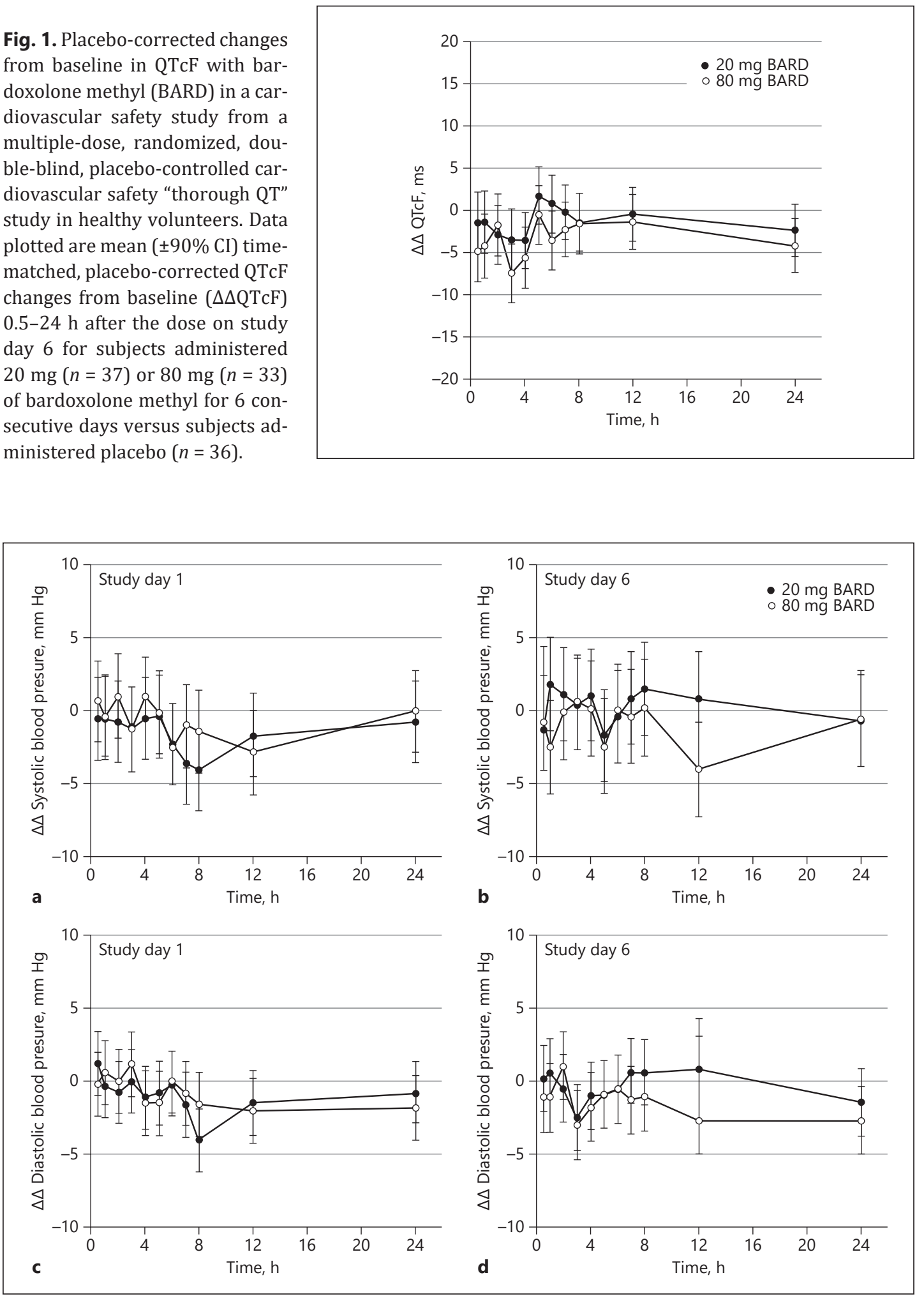

Fig. 2. Placebo-corrected changes from baseline in systolic $(\mathbf{a}, \mathbf{b})$ and diastolic blood pressure $(\mathbf{c}, \mathbf{d})$ in healthy volunteers administered bardoxolone methyl (BARD). Data are mean placebo-corrected systolic and diastolic blood pressure changes from baseline ( $\pm 90 \% \mathrm{CI}) 0-24 \mathrm{~h}$ after the dose on study day 1 (a, c) and study day $6(\mathbf{b}, \mathbf{d})$ in patients receiving 20 or $80 \mathrm{mg}$ of BARD. The final, published version of this article is available at http://www.karger.com/?doi=10.1159/000362906. 
Table 2. Summary of adverse events

\begin{tabular}{lcccl}
\hline \multirow{2}{*}{$\begin{array}{l}\text { Adverse } \\
\text { events }\end{array}$} & \multicolumn{2}{l}{ Subjects, $n(\%)$} & \\
\cline { 2 - 4 } & $\begin{array}{l}\text { placebo } \\
n=45\end{array}$ & \multicolumn{2}{l}{ bardoxolone methyl } & \begin{tabular}{l} 
moxifloxacin \\
\cline { 2 - 4 }
\end{tabular} \\
\cline { 3 - 4 } & & $\begin{array}{l}200 \mathrm{mg} \\
n=45\end{array}$ & $\begin{array}{l}80 \mathrm{mg} \\
n=44\end{array}$ & $n=45$ \\
\hline All & $14(31.1)$ & $16(35.6)$ & $25(56.8)$ & $11(24.4)$ \\
Increased ALT & 0 & $2(4.4)$ & $14(31.8)$ & 0 \\
Headache & $1(2.2)$ & $5(11.1)$ & $10(22.7)$ & $2(4.4)$ \\
Nausea & $2(4.4)$ & $5(11.1)$ & $7(15.9)$ & $3(6.7)$ \\
Dizziness & $3(6.7)$ & $3(6.7)$ & $2(4.5)$ & $3(6.7)$ \\
\hline
\end{tabular}

Includes treatment-emergent adverse events reported in $\geq 5$ subjects given bardoxolone methyl.

\section{Effects of Bardoxolone Methyl on QTcF}

Figure 1 shows placebo-corrected changes from baseline in QTcF for patients randomized to 20 or $80 \mathrm{mg}$ of bardoxolone methyl. Bardoxolone methyl was associated with small, dosedependent decreases from baseline in QTcF. Importantly, the upper limits of the 2-sided $90 \%$ CIs for $\Delta \Delta \mathrm{QTCF}$ were less than the prespecified significance threshold $(10 \mathrm{~ms})$ at all time points (post-study day 6 dose) for the 20- and 80-mg bardoxolone methyl groups (the highest upper bounds were 5.1 and $2.8 \mathrm{~ms}$ for the 20 - and 80 -mg dose group, respectively), demonstrating that bardoxolone methyl does not prolong the QTc interval to a clinically meaningful extent.

\section{Effects of Bardoxolone Methyl on Blood Pressure}

In Figure 2, the mean time-matched, placebo-corrected changes in systolic and diastolic blood pressure on study days 1 and 6 versus baseline are depicted for patients randomized to 20 or $80 \mathrm{mg}$ of bardoxolone methyl. In both bardoxolone methyl-treated groups, changes in blood pressure did not differ from changes in placebo-treated patients after 6 days of oncedaily administration.

\section{Adverse Events}

Overall, there were 163 treatment-emergent adverse events reported in 66 subjects during the study. No serious adverse events were reported, and none of the adverse events led to discontinuation of treatment during the study. Most adverse events reported during the study were mild in intensity and resolved or were improving at study conclusion. The overall number of subjects reporting adverse events was higher for the 80-mg bardoxolone methyl group than for the 20-mg bardoxolone methyl, placebo, or moxifloxacin groups (Table 2). The most frequently reported adverse event was increased alanine transaminase (ALT), which occurred only in the bardoxolone methyl treatment groups (occurring in 2 [4.4\%] subjects in the 20-mg group and in 14 [31.8\%] subjects in the 80-mg group). Adverse events such as headache, nausea, and dizziness were reported for all treatment groups.

\section{Discussion}

The main objective of this study was to evaluate the effects of bardoxolone methyl on QTc interval following once-daily administration of 20 and $80 \mathrm{mg}$ bardoxolone methyl for 6 consecutive days. No clinically significant increases were noted in QTcF at doses as high as 80 $\mathrm{mg}$, and the upper bounds of the $90 \%$ CIs on placebo-corrected changes in QTcF $(\Delta \Delta \mathrm{QTcF})$ at 
all measurement time points for both bardoxolone methyl treatment groups were less than the 10-ms significance limit. Values for QTcF tended to decrease with increasing bardoxolone methyl concentrations. These data are consistent with QTcF data from ECG assessments collected in BEACON, which showed that patients randomized to $20 \mathrm{mg}$ of bardoxolone methyl had decreases in QTcF at weeks 24 and 48 compared to baseline and placebo.

Despite the early termination of BEACON, patients randomized to bardoxolone methyl in BEACON experienced significantly improved kidney function. Lower serum creatinine concentrations (corresponding to higher eGFRs), along with lower serum concentrations of urea nitrogen, uric acid, and phosphorus were observed. In concert with increases in eGFR, reductions in serum magnesium were also observed in bardoxolone methyl-treated patients, and hypomagnesemia was reported as an adverse event in $21 \%$ of patients randomized to bardoxolone methyl compared with $6 \%$ of placebo patients [17]. Although low magnesium levels can increase the risk for arrhythmias, data from the present study demonstrate that there is no effect of bardoxolone methyl on QT interval, suggesting that the observed decreases in serum magnesium with bardoxolone methyl treatment are not associated with QTcF increases.

Additionally, the present study showed that bardoxolone methyl treatment had no effect on systolic or diastolic blood pressure in healthy subjects. No clear patterns or trends were evident in blood pressure on study days 1 or 6 following treatment with 20 or 80 mg bardoxolone methyl, and no statistically significant relationship was found between systolic or diastolic blood pressure and bardoxolone methyl concentrations. As previously reported, blood pressure was increased in the bardoxolone methyl group compared to the placebo group in BEACON [14] and analyses of phase 2 CKD studies conducted with bardoxolone methyl showed increases in both systolic and diastolic blood pressure were observed primarily in stage 4 CKD patients and not in stage 3 CKD patients. Together with previously reported data, the blood pressure data from the present study indicate that bardoxolone methyl treatment may differentially affect systemic hemodynamic status according to the clinical condition of subjects, with no clinically detectable effect in healthy volunteers or early-stage CKD patients, while fluid retention is apparently promoted without evidence of direct cardiotoxicity in patients with more advanced kidney dysfunction and other recognized risk factors which are associated with heart failure at baseline. Importantly, subsequent clinical trials with bardoxolone methyl have used the identified risk factors for heart failure from BEACON to exclude patients with elevated baseline B-type natriuretic peptide and a prior history of heart failure. No signs of overt fluid overload or subclinical measures of fluid retention, including meaningful changes in blood pressure or B-type natriuretic peptide, have been observed in those studies $[18,22,23]$, and support that prospectively enrolling patients who are not at risk for fluid retention may effectively mitigate the risk for fluid overload with bardoxolone methyl.

The most commonly reported adverse event in the present study was increased ALT. As observed in other clinical studies [16,17], transient increases in ALT were observed in the present study for patients receiving bardoxolone methyl; mean ALT values increased to a maximum on study day 7 that remained below $3 \times$ the upper limit of the population reference range (data not shown). Importantly, increases in ALT with bardoxolone methyl treatment are not associated with elevations in bilirubin levels or other signs of liver toxicity. Bardoxolone methyl also increases ALT and aspartate transaminase (AST) protein levels in cell lines derived from non-hepatic tissues, such as colon, skeletal muscle, and kidney [24]. These data suggest that bardoxolone methyl may regulate ALT and AST expression in multiple organs, and that the increases in transaminase levels observed in humans may be related to the pharmacology of the drug rather than liver toxicity. Notably, no reports of drug-induced liver injury have ever been reported with bardoxolone methyl treatment, and fewer hepatobiliary serious adverse events were reported in bardoxolone methyl-treated patients than in placebo patients in BEACON (4 vs. 8 patients, respectively) [17]. 
In summary, treatment with bardoxolone methyl was not associated with adverse cardiovascular effects on QT interval. Instead, improvements in kidney function have been consistently observed in multiple clinical studies with bardoxolone methyl, and the durable increases in eGFR with bardoxolone methyl were associated in BEACON with a significantly reduced likelihood of kidney failure outcomes, including end-stage renal disease and other validated surrogates ( $\geq 30 \%$ decline in eGFR or eGFR $<15 \mathrm{~mL} / \mathrm{min} / 1.73 \mathrm{~m}^{2}$ [25]). Bardoxolone methyl is currently being studied in a global phase $2 / 3$ study in patients with CKD due to the Alport syndrome (CARDINAL; NCT03019185), in a phase 2 study in US patients with other rare forms of CKD, including autosomal dominant polycystic kidney disease, type 1 diabetes, IgA nephropathy, and focal segmental glomerulosclerosis (PHOENIX, NCT03366337), and in a phase 3 study in Japanese patients with type 2 diabetes and CKD (AYAME, NCT03550443).

\section{Acknowledgments}

We acknowledge the supportive role of all investigators, support staff, and patients.

\section{Statement of Ethics}

The study was approved by the Institutional Review Board at the participating site and was conducted in accordance with the Declaration of Helsinki. All patients or subjects provided written informed consent.

\section{Disclosure Statement}

All authors are employees of Reata Pharmaceuticals.

\section{Funding Sources}

The study was sponsored by Reata Pharmaceuticals.

\section{Author Contributions}

All authors had full access to all data from the trial and approved the decision to submit for publication.

\section{References}

1 Dinkova-Kostova AT, Liby KT, Stephenson KK, Holtzclaw WD, Gao X, Suh N, et al. Extremely potent triterpenoid inducers of the phase 2 response: correlations of protection against oxidant and inflammatory stress. Proc Natl Acad Sci USA. 2005 Mar;102(12):4584-9.

2 Li J, Stein TD, Johnson JA. Genetic dissection of systemic autoimmune disease in Nrf2-deficient mice. Physiol Genomics. 2004 Aug;18(3):261-72.

3 Yoh K, Itoh K, Enomoto A, Hirayama A, Yamaguchi N, Kobayashi M, et al. Nrf2-deficient female mice develop lupus-like autoimmune nephritis. Kidney Int. 2001 Oct;60(4):1343-53.

4 Ma Q, Battelli L, Hubbs AF. Multiorgan autoimmune inflammation, enhanced lymphoproliferation, and impaired homeostasis of reactive oxygen species in mice lacking the antioxidant-activated transcription factor Nrf2. Am J Pathol. 2006 Jun;168(6):1960-74.

5 Yates MS, Tauchi M, Katsuoka F, Flanders KC, Liby KT, Honda T, et al. Pharmacodynamic characterization of chemopreventive triterpenoids as exceptionally potent inducers of Nrf2-regulated genes. Mol Cancer Ther. 2007 Jan;6(1):154-62. 
6 Sporn MB, Liby KT, Yore MM, Fu L, Lopchuk JM, Gribble GW. New synthetic triterpenoids: potent agents for prevention and treatment of tissue injury caused by inflammatory and oxidative stress. J Nat Prod. 2011 Mar; 74(3):537-45.

7 Ahmad R, Raina D, Meyer C, Kharbanda S, Kufe D. Triterpenoid CDDO-Me blocks the NF-kappaB pathway by direct inhibition of IKKbeta on Cys-179. J Biol Chem. 2006 Nov;281(47):35764-9.

8 Straus DS, Pascual G, Li M, Welch JS, Ricote M, Hsiang CH, et al. 15-deoxy-delta 12,14-prostaglandin J2 inhibits multiple steps in the NF-kappa B signaling pathway. Proc Natl Acad Sci USA. 2000 Apr;97(9):4844-9.

9 Serhan CN, Chiang N, Van Dyke TE. Resolving inflammation: dual anti-inflammatory and pro-resolution lipid mediators. Nat Rev Immunol. 2008 May;8(5):349-61.

10 Levonen AL, Landar A, Ramachandran A, Ceaser EK, Dickinson DA, Zanoni G, et al. Cellular mechanisms of redox cell signalling: role of cysteine modification in controlling antioxidant defences in response to electrophilic lipid oxidation products. Biochem J. 2004 Mar;378(Pt 2):373-82.

11 Wu QQ, Wang Y, Senitko M, Meyer C, Wigley WC, Ferguson DA, et al. Bardoxolone methyl (BARD) ameliorates ischemic AKI and increases expression of protective genes Nrf2, PPAR $\gamma$, and HO-1. Am J Physiol Renal Physiol. 2011 May;300(5):F1180-92.

12 Ma R, Bumeister R, Stidham R, Kambuj P, Sprouse M, Ferguson D, et al. Bardoxolone Methyl (BARD). Germany: Inhibits Inflammatory Signaling in Cultured Mesangial Cells. Poster ERA-EDTA Meeting Munich; 2010.

13 Ding Y, Stidham RD, Bumeister R, Trevino I, Winters A, Sprouse M, et al. The synthetic triterpenoid, RTA 405, increases the glomerular filtration rate and reduces angiotensin II-induced contraction of glomerular mesangial cells. Kidney Int. 2013 May;83(5):845-54.

14 Aminzadeh MA, Reisman SA, Vaziri ND, Khazaeli M, Yuan J, Meyer CJ. The synthetic triterpenoid RTA dh404 (CDDO-dhTFEA) restores Nrf2 activity and attenuates oxidative stress, inflammation, and fibrosis in rats with chronic kidney disease. Xenobiotica. 2014 Jun;44(6):570-8.

15 Pergola PE, Krauth M, Huff JW, Ferguson DA, Ruiz S, Meyer CJ, et al. Effect of bardoxolone methyl on kidney function in patients with T2D and Stage 3b-4 CKD. Am J Nephrol. 2011;33(5):469-76.

16 Pergola PE, Raskin P, Toto RD, Meyer CJ, Huff JW, Grossman EB, et al.; BEAM Study Investigators. Bardoxolone methyl and kidney function in CKD with type 2 diabetes. N Engl J Med. 2011 Jul;365(4):327-36.

17 de Zeeuw D, Akizawa T, Audhya P, Bakris GL, Chin M, Christ-Schmidt H, et al.; BEACON Trial Investigators. Bardoxolone methyl in type 2 diabetes and stage 4 chronic kidney disease. N Engl J Med. 2013 Dec;369(26): 2492-503.

18 Nangaku M, Shimazaki R, Akizawa T. Bardoxolone Methyl Improved GFR Measured by Standard Inulin Clearance: The TSUBAKI Study. J Am Soc Nephrol. 2017;28:B1.

19 Chin MP, Reisman SA, Bakris GL, O'Grady M, Linde PG, McCullough PA, et al. Mechanisms contributing to adverse cardiovascular events in patients with type 2 diabetes mellitus and stage 4 chronic kidney disease treated with bardoxolone methyl. Am J Nephrol. 2014;39(6):499-508.

20 Chin MP, Wrolstad D, Bakris GL, Chertow GM, de Zeeuw D, Goldsberry A, et al. Risk factors for heart failure in patients with type 2 diabetes mellitus and stage 4 chronic kidney disease treated with bardoxolone methyl. J Card Fail. 2014 Dec;20(12):953-8.

21 US Department of Health and Human Services, Food and Drug Administration, Center for Drug Evaluation and Research (CDER), Center for Biologic Evaluation and Research (CBER). Guidance for Industry. E14 Clinical Evaluation of QT/QTc Interval Prolongation and Proarrhythmic Potential for Non-Antiarrhythmic Drugs. Silver Spring, MD: US Food and Drug Administration;2005.

22 Oudiz RJ, Meyer C, Chin M, Feldman J, Goldsberry A, McConnell J, et al. Bardoxolone Methyl Evaluation in Patients with Pulmonary Arterial Hypertension (PAH). Initial data report from LARIAT: A phase 2 study of barodoxolone methyl in PAH patients on stable background therapy. Chest. 2015;148:639A.

23 Block GA, Pergola PE, Inker LA, McCullough PA, Chin MP, Meyer CJ, et al. Initial Data Report from "CARDINAL": A Phase 2/3 Study of Bardoxolone Methyl in Patients with Alport Syndrome. J Am Soc Nephrol. 2017;28:B3.

24 Miller G, Bumeister R, Laidlaw J, Kambuj P, Probst B, Ferguson DA, et al. Bardoxolone Methyl Transcriptionally Regulates Transaminase Levels and Increases Glutathione Levels. J Am Soc Nephrol. 2011;22:770A.

25 Chin MP, Bakris GL, Block GA, Chertow GM, Goldsberry A, Inker LA, et al. Bardoxolone Methyl Improves Kidney Function in Patients with Chronic Kidney Disease Stage 4 and Type 2 Diabetes: Post-Hoc Analyses from Bardoxolone Methyl Evaluation in Patients with Chronic Kidney Disease and Type 2 Diabetes Study. Am J Nephrol. 2018;47(1):40-7. 